\title{
Radiocarbon Dating and the Naqada Relative Chronology
}

\begin{abstract}
The Naqada relative chronology forms the main cultural framework for the Predynastic period of ancient Egypt. It was devised in the late nineteenth century by Flinders Petrie to facilitate understanding of the prehistoric origins of the Egyptian state. Petrie's approach served as the blueprint for similar systems across the world and formed the basis for the development of seriation. In this study, we test the reliability of the Naqada relative chronology as a dating tool against all the relevant radiocarbon information. The results show that the main blocks of the relative sequence do form a true chronology, but also indicate that the system is much less reliable at the level of individual phases. The nature of the discrepancies and the influence of the relative chronology on current understanding of Early Egypt are discussed.
\end{abstract}

\section{Introduction}

The first relative chronology based on the sequencing of artefacts was developed for the Predynastic period of ancient Egypt. The brainchild of Flinders Petrie, Sequence Dating (Petrie 1899) was an innovative response to the absence of clear stratigraphy at many of the key sites. The relative chronology soon became the main cultural framework for the Predynastic - the crucial period of time that demarcates the emergence of the Egypt state. Moreover, Petrie's methodology was a breakthrough for empirical archaeology and laid the groundwork for techniques such as seriation and artefact-based cladistics (Ford and Willey 1949; Brainerd 1951; O’Brien and Lyman 2000).

Petrie conceived his method whilst analysing the ceramic assemblages of the Upper Egyptian cemeteries of Naqada, Ballas and Diospolis Parva (Petrie and Quibell 1896; Petrie 1899). He began by defining more than 700 types of funerary ceramics and then dividing the full corpus into 9 main classes, largely on the basis of morphology and finish, but also on material composition (Petrie and Quibell 1896). He then focused his attention on the 900+ excavated tombs that contained 5 or more types of pottery. Petrie listed the types found in each grave on strips of card and then set about arranging them in order to minimise variation between adjacent cards. He defined such variation using qualitative terms like 'proportionate resemblance' and 'similarity of style'. His intention was to construct a continuum that showed incremental change in pottery styles over time. In addition, Petrie also looked for chronological information within individual ceramic classes, deducing that some types showed a 'degradation of form' with the passage of time. The archetypical example was the $\mathrm{W}$-ware (Wavy-handled pots). Petrie interpreted this class as having developed from globular shapes with wavy handles to cylindrical forms embellished with wavy decorations (Petrie 1899). Such assumptions were, however, highly informed by the evolutionary gradualism prevalent within the academic milieu of late $19^{\text {th }}$ century Britain (see Lane Fox 1870; 1875; Tylor 1871). Due to the subsequent hegemony of Petrie's chronology, such assumptions have had unintended consequences for the study of Early Egypt. One of the most persistent has been the view that the trajectory of Egyptian state formation mirrored the linear and 
incremental progression of the ceramic sequences. Much effort has been made over recent decades to explain how misleading this interpretation has been and how poorly matched it is to the archaeological evidence (Friedman 1994; Wengrow 2006; Dee et al. 2013).

Petrie's original matrix consisted of 50 groups assigned Sequence Dates (SD) 3080, numbers chosen deliberately to allow for extension at each end. The full sequence was divided into three major 'cultures', which Petrie considered to be culturally and chronologically distinct (Hendrickx 2006). He named these the Amratian (SDs 30-37), the Gerzean (SDs 38-60) and the Semainian (SDs 60-75). Over the course of the $20^{\text {th }}$ century, Petrie's groups were continually augmented and refined, most notably by Kaiser $(1956 ; 1957)$, who placed more emphasis on the spatial arrangement of the ceramics, and Hendrickx (1996; 2006) who synthesized evidence from a much greater number of excavations. But Petrie's original structure has remained remarkably intact, and the remnants of his three divisions are still evident in the current nomenclature Naqada I, II and III.

Table 1 outlines the Naqada relative dating system prior to phase IIIC1, the cultural period during which the state was founded. Over recent decades, confidence in the system has waned on account of its incongruity with some new archaeological evidence. Problems have included the absence of whole classes of ceramics, local stylistic and compositional variations, and differences in object clustering (Friedman 1994; Hendrickx 2006; Wengrow 2006). An even more fundamental challenge, however, has focused on how accurately the various phases actually reflect the passage of time - how reliable it is as a relative chronology. Verifying this assumption has proved highly challenging (e.g.: Savage 2001). Testing the chronology at the implied level of resolution (the whole Naqada period is thought not to exceed a millennium) would require absolute dates of decadal or even annual precision. Bayesian modelling can generate this sort of precision (Bronk Ramsey et al. 2010; Dee et al. 2013), but such analysis generally begins with the assumption the relative ordering is correct a priori. Directly comparing the age of individual contexts, or the ordering of specific artefacts, requires wholly independent measurement. Sub-centennial dating precision on individual samples is currently beyond the capability of most chronometric techniques, even high-precision radiocarbon $\left({ }^{14} \mathrm{C}\right)$ dating.

Lingering doubts about the chronology have caused some excavators to revert a more conservative version ${ }^{1}$ that consists of blocks of phases (see right-hand column, Table 1). Moreover, because it was the forerunner of all typological chronologies, the validity of the Naqada sequence has implications well beyond the field of Egyptian archaeology. Here, we collate the radiocarbon $\left.{ }^{14} \mathrm{C}\right)$ evidence pertaining to the Naqada relative chronology and determine in probabilistic terms whether either version (henceforth, Conventional or Simplified) actually does form a true chronology in absolute time.

\footnotetext{
${ }^{1}$ A workshop entitled The Origins of Nationhood: A New Chronology for the Formation of the Egyptian was held at University College London in March 2013. The clear majority of archaeologists present favoured the Simplified chronology.
} 


\begin{tabular}{|c|l|c|}
\hline $\begin{array}{c}\text { Conventional } \\
\text { Naqada } \\
\text { Chronology }\end{array}$ & \multicolumn{1}{|c|}{ Some Key Features } & $\begin{array}{c}\text { Simplified } \\
\text { Naqada } \\
\text { Chronology }\end{array}$ \\
\hline IA & $\begin{array}{l}\text { B-ware, C-ware and P-ware dominate; } \\
\text { styles diversify over time; rhomboidal } \\
\text { palettes prevalent in IIC }\end{array}$ & IA-IB \\
\hline IB & $\begin{array}{l}\text { C-ware gradually disappears; R-ware } \\
\text { emerges and P-wares become more } \\
\text { diverse; fish-shaped palettes appear }\end{array}$ & \\
\hline IC & $\begin{array}{l}\text { R-ware dominates; D-ware and W-ware } \\
\text { appear; B-ware and rhomboidal palettes } \\
\text { decline IIA }\end{array}$ & IIC-IID \\
\hline IIB & $\begin{array}{l}\text { D-ware and P-ware decline; L-ware } \\
\text { increases dramatically; W-ware reduced to } \\
\text { banded decoration; vessel W62 exhibiting } \\
\text { the net pattern is diagnostic of IIIA2 }\end{array}$ & \\
\hline IIC & $\begin{array}{l}\text { L-ware and W-ware dominate, the latter } \\
\text { now cylindrical incised jars; R-ware } \\
\text { decline, especially pointed-base styles }\end{array}$ & \\
\hline IID & IIIB \\
\hline IIIA1 &
\end{tabular}

Table 1. The Naqada relative chronology for the Predynastic period. The left-hand column gives the alphanumeric titles for each phase of the Conventional chronology. The right-hand column shows the blocks of phases that make up the Simplified chronology. The central column outlines some of the main trends in the type and distribution of ceramic classes during this period (see Hendrickx 2006 for more detail).

\section{Verification by radiocarbon dating}

As with many chronometric techniques, raw ${ }^{14} \mathrm{C}$ dates are estimates of the mean of a Normally distributed random variable. Thus, multiple measurements on the same sample are naturally scattered over a range of values (see Ward and Wilson 1978; Buck 1991). With modern instrumentation, this range can be limited to about one hundred ${ }^{14} \mathrm{C}$ years (95\%). However, this point exemplifies the first caveat when trying to order samples using raw ${ }^{14} \mathrm{C}$ measurements: two identically aged materials can legitimately differ by tens of ${ }^{14} \mathrm{C}$ years. Secondly, in order for ${ }^{14} \mathrm{C}$ measurements to be converted to calendrical dates, they need to be compared with a reference dataset known as a calibration curve (see Bronk Ramsey 2006; Reimer et al. 2009). For a given sample, this step usually results in a calendar date range that is even broader still (ca. 200-300 years, 95\% probability). Finally, there is the question of the congruence of the biological age of the sample and its context. ${ }^{14} \mathrm{C}$ dates can only be obtained on biogenic materials (human, animal and plant remains) and not on the ceramics upon which the Naqada relative dating system is based. That is, they represent the age of the organics found in association with the pottery, and hence depend on the 
material history of the former and not the latter (see Dee et al. 2012, for examples of inappropriate sample materials). However, discrepancies arising in this manner can be mitigated by careful sample selection and measuring more than one type of material from the same context.

\section{Methods}

Our rationale involved collating all ${ }^{14} \mathrm{C}$ dates that could also be assigned Naqada relative dates (IA-IIIB) and then quantitatively testing the ordering of each chronology (Conventional and Simplified, Table 1) using the Order function in OxCal (Bronk Ramsey 1995; 2009, version 4.2). In order to maximise the validity of the absolute-relative dating comparison, a number of parameters had to be controlled:

- Context type: Naqada dates are sometimes assigned to habitation sites. In fact, more than $100{ }^{14} \mathrm{C}$ dates have been published on samples from such contexts (see Ginter and Kozlowski 1994; Midant-Reynes and Buchez 2002). However, extending the system to habitation contexts involves an additional step away from the system's evidence base, so these results were deemed inadmissible for our study. Individual graves that were unplundered in antiquity were prioritised, but contexts exhibiting minor disturbance were not automatically excluded, because of the nature of the samples dated (human remains, tomb structural material, such as wood and reed-matting).

- Sample Quality: it was imperative that the sample's age coincided with the burial event as closely as possible. Accordingly, we prioritised materials that exhibited minimal inbuilt age and excellent certainty of association (see Waterbolk 1971; Dee et al. 2012). Samples regarded as unreliable by the excavators were removed and laboratory quality control data associated with the ${ }^{14} \mathrm{C}$ dates were also taken into account (for examples, see Brock et al. 2010).

- Subjectivity and precision of assignment: the allocation of Naqada relative dates is open to a degree of subjectivity. We utilised assignments made by the foremost scholar in the field, Dr Stan Hendrickx, wherever possible. Otherwise, those made by the original excavators were used. Where the assignment was too vague to fit within either the Conventional or Simplified relative sequence, the ${ }^{14} \mathrm{C}$ result could not be used.

- Geographical location: it is not known how synchronous the cultural transitions of the Predynastic were across Egypt. Indeed, even if the system is correctly ordered, it is likely that some locations led or lagged behind others. In the ideal scenario, therefore, samples from just one site would be employed.

Our initial dataset comprised all the ${ }^{14} \mathrm{C}$ results available for Predynastic funerary contexts. Data were found for every phase from IB to IIIA2, but none specifically for phases IA or IIIB that matched the criteria given above. In all 91 results were collated, of which 67 were employed by of Dee et al. (2013), and 
another 16 are unpublished data from the same research programme. The remaining 8 results came from a study of Minshat Abu Omar published by Kroeper (2003). The 91 dates are shown in Table S1 in the supplementary material, and in the online Egyptian Radiocarbon Database:

https://c14.arch.ox.ac.uk/egyptdb/db.php

Nine dates were removed from the dataset as a result of the Sample Quality criterion above and 4 further results, on wood and charcoal, to comply with the Inbuilt Age requirement. However, the suite of wood results from Umm el-Qaab were retained because the original publication explicitly stated that the wood:

'typically had an age of 10 to $20 \mathrm{yr}$. In the case of the excavated important tombs, reuse of wood is unlikely.' Gosdorf et al. (1998)

The relative assignments for 7 of the remaining samples were too imprecise to fit the Simplified chronology, and 9 further assignments were too broad for the individual phases of the Conventional sequence. The only specific location that furnished enough data for meaningful analysis was Naqada and Ballas. The results for these adjacent and contemporaneous cemeteries were also tested against both the Conventional and Simplified chronologies. A breakdown of each dataset is given in Table 2 .

Mathematically determining the most probable order of the Naqada phases involved allocating the ${ }^{14} \mathrm{C}$ dates for each phase to its own OxCal Phase of uniform prior density (Buck et al. 1991). Each OxCal Phase was then delimited by Boundaries and included in its own OxCal Sequence. The Sum feature was added to each Phase to calculate its average date. The models also used the order function to estimate the most likely ordering of the average dates. The ordering of the start and end Boundaries of each Phase was also calculated. An Outlier probability of $5 \%$ was applied to all samples to minimise the impact of any spurious results. The computer code for the OxCal models is given in the supplementary material.

\begin{tabular}{|l|l|c|c|}
\hline \multirow{4}{*}{ Initial } & Dataset & No. ${ }^{14}$ C Samples & No. ${ }^{\mathbf{1 4}}$ C Dates \\
\cline { 2 - 4 } & All & 85 & 91 \\
\cline { 2 - 4 } & Poor quality & 7 & 9 \\
\cline { 2 - 4 } & Possible inbuilt age & 4 & 4 \\
\hline \multirow{3}{*}{ Egypt } & All & 74 & 78 \\
\cline { 2 - 4 } & Simplified & 67 & 71 \\
\cline { 2 - 4 } & Conventional & 60 & 62 \\
\hline \multirow{2}{*}{$\begin{array}{l}\text { Naquada and } \\
\text { Ballas }\end{array}$} & All & 23 & 27 \\
\cline { 2 - 4 } & Simplified & 19 & 23 \\
\cline { 2 - 4 } & Conventional & 14 & 16 \\
\hline
\end{tabular}

Table 2. Breakdowns of the number of samples and individual ${ }^{14} \mathrm{C}$ dates (including replicated measurements) in each of the datasets.

\section{Results}

The most informative outputs of this approach for understanding the Predynastic period of Egypt came from comparing the average dates for each 
block of phases (Simplified chronology) and each individual phase (Conventional chronology). The probabilities for the ordering of these averages are given in Table 3 (Simplified chronology) and Table 4 (Conventional chronology). Specifically, the tables provide the probability that the average date for the phase (or block of phases) listed in the left-hand column is older than the average date for the remaining phases. For example, the probability the average date for phase IIC is older than the average date for phase IIIA2 is 0.92 (Table 4). Modelled probability density functions for the average dates are given in Figure 1.

The models also generated probabilities for the likely ordering of the beginnings and ends of each phase. However, because cultural phases of this kind rarely have distinct start and end points, the value of such comparisons for datasets of this size is unclear. Nonetheless, tables displaying the results for the boundaries are given in the supplementary material.

\begin{tabular}{|c|c|c|c|c|c|c|}
\hline \multirow{2}{*}{$\begin{array}{l}\text { Block of } \\
\text { Phases }\end{array}$} & \multirow{2}{*}{$\begin{array}{c}\text { No. } \\
\text { Samples }\end{array}$} & \multirow[t]{2}{*}{ No. Sites } & \multicolumn{4}{|c|}{ Probability } \\
\hline & & & IA-IB & IC-IIB & IIC-IID & $\begin{array}{l}\text { IIIA1- } \\
\text { IIIA2 }\end{array}$ \\
\hline \multicolumn{7}{|c|}{ Egypt Dataset } \\
\hline IA-IB & 1 & 1 & - & 0.65 & 0.97 & 0.99 \\
\hline IC-IIB & 19 & 8 & 0.35 & - & 0.98 & 0.99 \\
\hline IIC-IID & 31 & 9 & 0.03 & 0.02 & - & 0.62 \\
\hline IIIA1-IIIA2 & 8 & 2 & 0.01 & 0.01 & 0.38 & - \\
\hline \multicolumn{7}{|c|}{ Naqada and Ballas Dataset } \\
\hline IA-IB & 0 & 1 & - & - & - & - \\
\hline IC-IIB & 10 & 1 & - & - & 0.91 & 1.00 \\
\hline IIC-IID & 7 & 1 & - & 0.09 & - & 0.91 \\
\hline IIIA1-IIIA2 & 2 & 1 & - & 0.00 & 0.09 & - \\
\hline
\end{tabular}

Table 3. Radiocarbon-based probabilities relating to the ordering of the Simplified Naqada chronology.

\begin{tabular}{|l|c|c|c|c|c|c|c|c|c|c|}
\hline Phase & No. & No. & \multicolumn{8}{|c|}{ Probability } \\
\cline { 5 - 11 } & Samples & Sites & IB & IC & IIA & IIB & IIC & IID & IIIA1 & IIIA2 \\
\hline Egypt Dataset \\
\hline IB & 1 & 1 & - & 0.72 & 0.65 & 0.75 & 0.83 & 0.97 & 0.97 & 0.99 \\
\hline IC & 9 & 5 & 0.28 & - & 0.37 & 0.48 & 0.62 & 0.81 & 0.81 & 0.88 \\
\hline IIA & 3 & 2 & 0.35 & 0.63 & - & 0.66 & 0.79 & 0.97 & 0.97 & 0.99 \\
\hline IIB & 7 & 4 & 0.25 & 0.52 & 0.34 & - & 0.68 & 0.91 & 0.91 & 0.96 \\
\hline IIC & 10 & 5 & 0.17 & 0.38 & 0.21 & 0.32 & - & 0.77 & 0.76 & 0.92 \\
\hline IID & 21 & 6 & 0.03 & 0.19 & 0.03 & 0.09 & 0.23 & - & 0.49 & 0.78 \\
\hline IIIA1 & 6 & 1 & 0.03 & 0.19 & 0.03 & 0.09 & 0.24 & 0.51 & - & 0.79 \\
\hline IIIA2 & 2 & 1 & 0.01 & 0.12 & 0.01 & 0.04 & 0.08 & 0.22 & 0.21 & - \\
\hline Naqada & and Ballas Dataset & & & & & & & \\
\hline IB & 0 & 1 & - & - & - & - & - & - & - & - \\
\hline IC & 3 & 1 & - & - & 0.14 & 0.15 & 0.61 & 0.78 & - & 1.00 \\
\hline IIA & 1 & 1 & - & 0.86 & - & 0.49 & 0.85 & 0.89 & - & 1.00 \\
\hline
\end{tabular}




\begin{tabular}{|l|l|l|l|c|c|c|c|c|c|c|}
\hline IIB & 2 & 1 & - & 0.85 & 0.51 & - & 0.85 & 0.88 & - & 1.00 \\
\hline IIC & 3 & 1 & - & 0.39 & 0.15 & 0.15 & - & 0.65 & - & 0.92 \\
\hline IID & 3 & 1 & - & 0.22 & 0.11 & 0.12 & 0.35 & - & - & 0.82 \\
\hline IIIA1 & 0 & 1 & - & - & - & - & - & - & - & \\
\hline IIIA2 & 2 & 1 & - & 0.00 & 0.00 & 0.00 & 0.08 & 0.18 & - & - \\
\hline
\end{tabular}

Table 4. Radiocarbon-based probabilities relating to the ordering of the Conventional Naqada chronology.
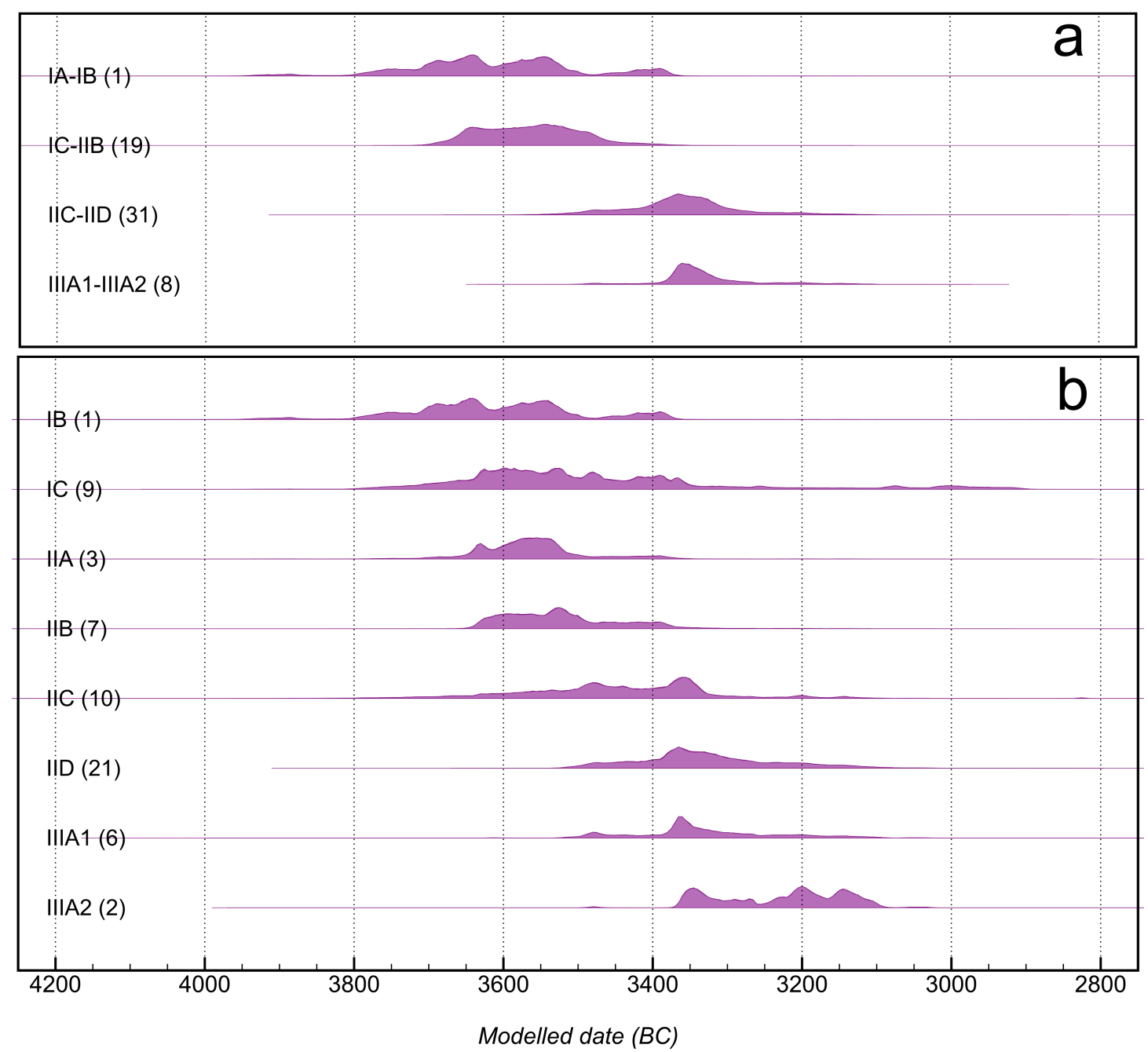

Figure 1. Modelled probability density functions for the average dates for the Simplified chronology (1a) and Conventional chronology (1b). The number of samples used for each average is given in brackets.

\section{Discussion}

Our results provide quantitative support for the ordering of the Simplified Naqada chronology. That is to say, the available ${ }^{14} \mathrm{C}$ evidence concurs with the established understanding that the three blocks IC-IIB, IIC-IID, and IIIA1-IIIA2 follow each other in absolute time. This statement holds for Egypt as a whole, as well as for the site of Naqada and Ballas, specifically. Too little data is available to determine whether IA-IB precedes these three blocks, but the one measurement that has been made does indeed meet this expectation. In spite of this affirmation 
of the relative chronology, our results also show that there is significant overlap between the blocks of phases. Thus, no assurance can be given that a randomly selected funerary context from one block will definitely precede one from the succeeding block. This ambiguity is most apparent between IIC-IID and IIIA1IIIA2 where the probability the ordering is correct is just 0.62 .

The ordering of the Conventional Naqada chronology is much less secure. Here, the ${ }^{14} \mathrm{C}$ evidence calls into question whether phases IC, IIA and IIB form a chronological sequence at all and whether or not phase IID truly precedes IIIA1. Both of these assumptions are now examined in more detail.

Table 4 shows that 19 good-quality ${ }^{14} \mathrm{C}$ dates were obtained for phases IC, IIA and IIB from a range of different sites. However, the results obtained from our comparison of these dates contradict the expected ordering of the phases. In particular, our results suggest IC is not the earliest but in fact the latest of the three phases, although the likelihood that IC precedes IIB is almost even (0.48). Whilst there are only 6 samples for these phases from Naqada and Ballas, it is still pertinent to note that these dates also suggest that phase IC does not occur before IIA or IIB. Further measurements from the one location are certainly required to confirm this observation, to ensure the discrepancy does not just reflect the pace of acculturation between sites. Nonetheless, the assumption that phases IC, IIA and IIB form a chronology runs contrary to the available absolute dating information.

It has already been noted that there is significant overlap between blocks IIC-IID and IIIA1-IIIA2 in absolute time. Drilling down to the level of individual phases, it becomes clear this overlap centres on the contiguity of phases IID and IIIA1. The average date for phase IIC is clearly older than the averages for IID, IIIA1 and IIIA2, with the latter being the youngest of the four (Table 4). However, the probability IID is older than IIIA1 is 0.49 . That is to say, the two phases essentially cannot be distinguished chronologically. Although a good number of dates are available for both the phases, all of the samples identified as IIIA1 were obtained from Cemetery $U$ at Abydos. Thus, the data could also be interpreted as indicating that the phase IIIA1 occurred first at Abydos, whilst phase IID was still prominent elsewhere. However, even if the two phases only occurred contemporaneously at different sites, this finding still firmly circumscribes the application of the artefact-based method for inter-site comparisons.

The results of this study rekindle fundamental questions about the purpose of artefact-based sequences in Predynastic Egypt and archaeology in general. Essentially two questions must be addressed. The first is whether the sequences always and unequivocally constitute a true chronology or just a continuum of different typologies. If they do not reflect the passage of time, is the approach not potentially misrepresenting the processes of cultural change in question by structuring them as orderly and gradual? Such systems run the risk of smoothing over irregularities in the true tempos of change that underlie the material forms. Secondly, the results suggest the raison d'etre of categorizing artefacts in this manner must be re-examined. Even if the approach does not provide precise dating information, it may still be an expedient way of arranging the objects in 
order to analyse their function and cultural value. More serious doubts must be confronted if the procedure facilitates neither chronological nor cultural analysis.

In the case of Predynastic Egypt, the systematic organisation of artefactual remains has provided the basic framework for analysing the profound sociocultural developments of the period. The findings of this study suggest this pottery-based chronology is only reliable in its most simplified form. Relying on the ordering of individual phases of the chronology is unsustainable on the basis of current chronometric evidence, and may be misrepresenting the temporality of Egyptian state formation.

\section{Conclusions}

By statistically analysing the full set of ${ }^{14} \mathrm{C}$ dates relating to Predynastic Egypt, our study examined whether the established Naqada relative dating system represented a true chronology. Although more high-quality data is required to bolster the patterns observed, our findings confirm that the main blocks of the relative sequence do offer reliable dating information. However, the results also cast doubt on the chronological integrity of the full Naqada sequence, and imply that the ordering of each of the individual phases may not be correct.

\section{References}

Brainerd, G. W. (1951). The place of chronological ordering in archaeological analysis. American Antiquity 16(4): 301-13.

Brock, F., Higham, T. F. G., Ditchfield, P., Bronk Ramsey, C. (2010). Current pretreatment methods for AMS radiocarbon dating at the Oxford Radiocarbon Accelerator Unit (ORAU). Radiocarbon 52(1): 103-112.

Bronk Ramsey C. 1995 Radiocarbon calibration and analysis of stratigraphy: the OxCal program. Radiocarbon 37(2), 425-430.

Bronk Ramsey, C., Buck, C. E., Manning, S. W., Reimer, P. and van der Plicht, H. (2006). Developments in radiocarbon calibration for archaeology. Antiquity 80(310): 783-798.

Bronk Ramsey, C. (2009). Bayesian Analysis of Radiocarbon Dates. Radiocarbon 51(1): 337-360.

Bronk Ramsey, C., Dee, M. W., Rowland, J. M., Higham, T. F. G., Harris, S. A., Brock, F., Quiles, A., Wild, E. M., Marcus, E. S., and Shortland, A. J. (2010). Radiocarbonbased chronology for dynastic Egypt. Science 328 (5985): 1554-1559.

Buck, C. E., Litton, C. D., Smith, A. F. M. (1991). Calibration of Radiocarbon Results Pertaining to Related Archaeological Events, Journal of Archaeological Science 19: 497-512.

Dee, M. W., Rowland, J. M., Higham, T. F. G., Shortland, A. J., Brock, F., Harris, S. A., Bronk Ramsey, C. (2012). Synchronising radiocarbon dating and the Egyptian 
historical chronology through improved sample selection. Antiquity 86: 868883.

Dee, M. W., Wengrow, D. W., Shortland, A. J., Stevenson, A., Brock, F., Girdland Flink, L. and Bronk Ramsey, C. (2013). An absolute chronology for early Egypt using radiocarbon dating and Bayesian Statistical modelling. Proceedings of the Royal Society $A$ (in press)

Friedman, R. F. (1994). Predynastic settlement ceramics of Upper Egypt: a comparative study of the ceramics of Hemamieh, Nagada, and Hierakonpolis, Department of Near Eastern Studies, University of California, Berkeley, University Microfilms International, Ann Arbor.

Ford, J. A. and Willey, G. R. (1949). Surface survey of the Virui Valley, Peru. Literary Licensing: New York.

Ginter, B. and Kozlowski, J. K. (1994). Predynastic Settlement near Armant. Heidelberg: Heidelberger Orientverlag.

Hendrickx, S. (1996). The relative chronology of the Naqada culture: problems and possibilities. In Aspects of Early Egypt, ed. Spencer, J., 36-69, London: British Museum Press.

Hendrickx, S. (2006). Predynastic - Early Dynastic Chronology. In Ancient Egyptian Chronology, eds. Hornung, E., Krauss, R. and Warburton, D. A., 55-93, Leiden: Brill.

Kaiser, W. (1956). Stand und probleme der Agyptischen vorgeschichtsforschung. Zeitschrift fur Agyptische Sprache und Altertumskunde 81: 87-109.

Kaiser, W. (1957). Zur inneren chronologie der Nagadakultur. Archaeologia Geographica 6: 69-77.

Kroeper, K. (2003). Radiocarbon and thermoluminescence dates from the Pre/Early Dynastic cemetery of Minshat Abu Omar (North-Eastern Nile Delta). In Cultural markers in the Later Prehistory of Northeastern Africa and Recent Research Studies in African Archaeology 8, eds. L. Krzyżaniak, K. Kroeper and M. Kobusiewicz, 227-249, Poznan: Poznan Arhcaeological Museum.

Lane Fox, A. H. (1870). Primitive warfare. Part III; On the resemblance of the weapons of early races, their variations, continuity and development of form metal period. Royal United Service Institute Journal 13: 509-539.

Lane Fox, A. H. (1875). On the principles of classification adopted in the arrangement of his anthropological collection, now exhibited in the Bethnal Green Museum. Journal of Anthropological Institute 4: 293 - 308. 
Midant-Reynes, B. and Buchez, N. (2002). Adaima I: Économie et Habitat. Cairo: Fouilles de l'Institut Français d'Archéologie Orientale 45.

O'Brien, M. J. and Lyman, R. L. (2000). Meeting theoretical and methodological challenges to the future of evolutionary archaeology. Review of Archaeology 20: 14-22.

Petrie, W. M. F. 1899. Sequences in prehistoric remains. Journal of the Anthropological Institute of Great Britain and Ireland 3/4: 295-301.

Petrie, W. M. F. and Quibell, J. E. (1896). Naqada and Ballas 1895. London: Bernard Quaritch

Reimer, P. J., Baillie, M. G. L., Bard, E., Bayliss, A., Beck, J. W., Blackwell, P. G., Bronk Ramsey, C., Buck, C. E., Burr, G. S., Edwards, R. L., Friedrich, M., Grootes, P. M., Guilderson, T. P., Hajdas, I., Heaton, T. J., Hogg, A. G., Hughen, K. A., Kaiser, K. F., Kromer, B., McCormac, F. G., Manning, S. W., Reimer, R. W., Richards, D. A., Southon, J. R., Talamo, S., Turney, C. S. M., van der Plicht, J. and Weyhenmeyer, C. E. (2009). IntCal09 and Marine09 radiocarbon age calibration curves, 0-50,000 years cal BP. Radiocarbon 51(4): 1111-1150.

Savage, S. H. (2001). Towards an AMS radiocarbon chronology of Predynastic Egyptian ceramics. Radiocarbon 43(3): 1255-1277.

Tylor, E. B. (1871). Primitive Culture. London: John Murray.

Ward, G. K. and Wilson S. R. (1978) Procedures for comparing and combining radiocarbon age determinations: a critique. Archaeometry 20(1): 19-31.

Wengrow, D. (2006). The Archaeology of Early Egypt. Cambridge: Cambridge University Press.

Waterbolk, H. T. (1971). Working with Radiocarbon Dates. Proceedings of the Prehistoric Society 37: 15-33. 